Mr. Stokes then read the following paper:-

\title{
THE ESTIMATION OF FAT IN MILK.
}

By A. H. STокеS.

IN the Berichte, vol. xxiv., p. 2204, there is described and figured by E. Molinari, an apparatus for rapidly estimating fat in milk. It is also described and illustrated in the last number of The AnaLyst. The apparatus is very delicate and, as figured, exceedingly difficult to clean. It is claimed that an analysis would take from 30 to 35 minutes, though if you sum up the times given by the inventor for each step of the process, it will take at least 50 minutes. But then, as a fat determination can, with only a simple tube, already be performed equally accurately in 20 minutes, there is no gain of rapidity. If it requires, as it probably would, half an hour besides to clean up the apparatus, there would be a great loss of time.

The idea of the apparatus is to prevent any transference from one vessel to another; the fat is set free, washed and weighed all in the same vessel.

I have devised a far simpler apparatus which will do this equally effectually.

It consists (see fig 1 ) of an Erlenmeyer flask of about 50 c.c. capacity, to the neck

* See abstract in this Journal, page 235. 
of which is joined a bulb of about 60 c.c. capacity terminating at the apex in a short glass tube with a tap to it. At the neck, where the bulb joins the flask, is a short side tube which can be closed by a cork. It is used thus :-

After being weighed, 10 grammes or 10 c.c. of milk are placed in the flask, heated almost to boiling, and about 10 c.c. of strong $\mathrm{HCl}$ added, this mixture is boiled over a flame for about one minute, left hot for about three minutes, then cooled down and ether poured in nearly up to the neck. The tap is closed, the cork inserted and the apparatus well shaken and then left for about five minutes to rest with the tap end downwards. The tap is now opened and as much as possible fo the acid liquid allowed to run out. The tap is closed, the cork taken out and about 10 c.c. of water run in and shaken with the ether and allowed to run out again through the tap; after standing awhile a second quantity of water is is thus used.

Finally, the tap is closed, the side tube connected to a condenser, the ether distilled

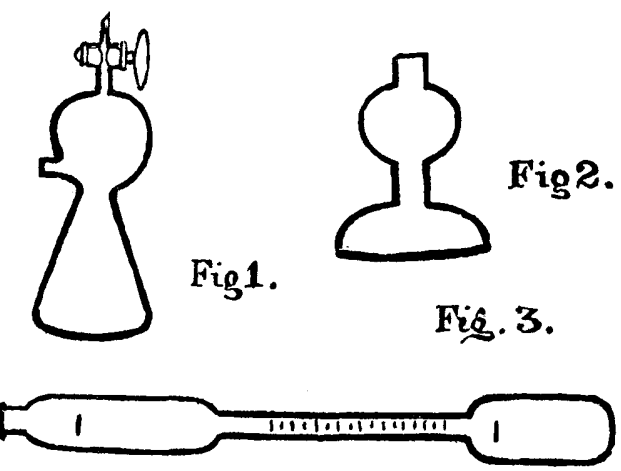
off, and the apparatus with its residual fat placed in the water-bath to dry. This drying, I find, takes a very long time.

The apparatus is very simple. The fat never leaves the apparatus after the milk is put into it but is treated and weighed all in the same vessel; no calculation is required. The objections to it are the difficulty of running off the acid or aqueous fluid so close as to leave none in the flask, or, on the other hand, to let none of the ethereal solution escape; the flask, being wet inside with water, takes a long time, sometimes hours, drying.

A simpler and quicker process is the use of another piece of apparatus (fig. 2), in which a 25 c.c. flask, having a neck of $\frac{3}{4}$-inch diameter and one inch long, is surmounted by another flask of about 35 c.c. capacity, terminating with a mouth of $\frac{3}{4}$-inch diameter. Into this 10 grammes or 10 c.c. of milk are placed; it is then heated on the water-bath, directly the milk is near $100^{\circ} \mathrm{C}$. the $\mathrm{HCl}$ is poured up to a mark near the beginning of the neck. By thus heating the milk before adding acid, no clots of curd are formed. After boiling for about one minute and leaving it hot for three minutes, it is cooled by placing it in a basin of water; the shape of the apparatus makes it float easily, so that there is no danger of its being immersed, however deep the water may be. It is now filled with ether up to about the middle of the upper bulb, a cork is inserted in the mouth and the whole violently shaken. On letting it stand about three minutes it will be found that the brown acid liquid comes up to the middle of the neck with a very slight layer of fluffy white casein between it and the ether.

Taking out the cork, a double tube arrangement like that of the ordinary washbottle is inserted. The cork of this should not be of indiarubber, but of ordinary cork, for two reasons : first, because a glass tube does not slide easily in rubber exposed to ether 
vapour; second, to avoid any chance of a solution of rubber being weighed off as fat. The longer tube of this is forced down till it almost touches the casein layer. A weighed flask is placed under the upper end of the tube, and by blowing into the other tube the fat-ether solution is driven into the weighed flask. About 10 c.c. more ether is placed in the apparatus and the whole shaken; after three minutes settling this ether is added to the first quantity. Another repetition of this leaves the liquid practically free from fat. The weighed flask is connected to a condenser and the ether distilled off. I find that if the flask is almost entirely immersed in boiling water, the ether does not boil violently, but is rapidly and quietly distilled off.

In fact, it will evaporate as quickly as if placed in an open dish on the water-bath. The flask is now dried in the air-bath for fifteen minutes and then weighed. The weight of fat multiplied by 10 gives the percentage if 10 grammes of milk were taken. If 10 c.c. were taken it is only necessary to divide the weight of fat by the specific gravity of the milk. In about 30 minutes the whole process may be completed.

With both pieces of apparatus I have obtained results identical with the calculated results and with those of the paper-coil process. In both cases the acid liquid and the washings are put into residue bottles and the ether afterwards recovered, so that hardly any ether is lost.

The principles of these are just the reverse of one another; from one the acid solution is expelled, from the other the ethereal solution is expelled. Apparatus No. 2 is by far the quicker, easier and less liable to error. It embodies Mr. A. H. Allen's principle of doing away with calculation; the narrow neck in the middle enables the ether to be drawn off almost entirely each time; the shortness of the bulb containing the ether allows the acid to settle out in the quickest possible time after shaking.

But neither of these methods is so rapid as the use of the long tube described in ANaLYST XVI., p. 71, a figure of which I show to-night (fig. 3) alongside of the original short tube. By the use of a centrifugal apparatus giving about 3,000 revolutions per minute, I can separate in this the ethereal layer in one minute, and, working in the way described in the Chemical News, of November 1st, 1889, can complete a fat extraction in 15 minutes; without the centrifugal apparatus the fat has been frequently determined in 20 minutes accurately in my laboratory.

Before trying any special apparatus, I experimented to see if there could be any destruction or loss of fat. I boiled known weights of butter-fat with $\mathrm{HCl}$ and water, extracted with ether, and recovered exactly the same amount of fat I put in, unaltered I took quantities of the brown acid liquid after it was done with, and found it to be absolutely free from any fat. The fat obtained in the other cases I have examined and found to be nothing else but butter-fat.

I experimented with ether containing known percentages of alcohol; up to $1 \frac{1}{2}$ per cent. alcohol does not interfere with the process.

Ether containing fat can be blown off or pipetted off just as easily as water. I tried other solvents than ether and other acids than $\mathrm{HCl}$. 
Occasionally on boiling milk with $\mathrm{HCl}$ and shaking it with ether, it forms a gelatinous mass from which the ether will not readily separate. This is usually due to not having boiled the two together long enough. On the other hand, too long boiling causes the casein to form bulky black flakes. The boiling may safely last from one to three minutes. If a milk does not turn the usual dark brown colour after three minutes' you may be sure it has been watered.

After a practical experience of every known method of fat extraction of milk, and a three years' special devotion to this method, I can assure the Society that there is no other method that at present can possibly compare with it for accuracy, simplicity, rapidity and cheapness, whether applied to cream, whole milk, skim milk, sour milk or condensed milk (sweetened or unsweetened).

No analyst of my acquaintance after trying this method has gone back to any other, and $\mathrm{I}$ know now, some dozen who habitually practise it.

To my assistant, Mr. W. N. Yarrow, I am indebted for the diagrams shown to-night.

I am pleased to bear testimony to the wonderful way in which fats thus determined agree with the calculated results given in the admirable table of Messrs. Hehner and Richmond in The ANalyst, XIII., p. 26.

\section{Discussion.}

Mr. Cassal said that while the special object of Mr. Stokes' paper was not quite clear, all would, no doubt, agree, that the Werner Schmid process was very valuable. The minute description of the pieces of apparatus represented by the diagrams appeared to be hardly necessary. The apparatus, described at such length by Mr. Stokes, seemed to be ingenious, but then Mr. Stokes had said that it should not be employed, as it was no use, and that it was almost impossible to clean it and dry it. He submitted, therefore, that this apparatus would not commend itself to the members of the Society. Mr. Stokes had described another piece of apparatus, which closely resembled a wash bottle. Mr. Stokes stated that he originally used a straight tube, of which an illustration was before them. A highly satisfactory point about the Werner Schmid process as amended, was, that after extracting with ether, one could blow out the whole of the ethereal solution by means of the apparatus suggested by Mr. Chattaway, evaporate it, and weigh the total amount of fat. The removal of a measured portion of the solution, by the reading off of the residual portion, was very undesirable in such a process, and formed a source of error. When, without unduly increasing the time legitimately required for such operations, one could obtain and weigh the whole of the fat in the portion of milk taken for analysis, he did not think that there was any advantage to be gained by the measurement modification sufficient to compensate for the risk. He himself had found that excellent results could be obtained by the WernerSchmid process, and Mr. Stokes was to be thanked for having introduced it to their notice. $\mathrm{He}$ (Mr. Cassal) had found that accurate results were most satisfactorily obtained 
by the use of a simple tube provided with the wash-bottle arrangement, suggested by Mr. Chattaway, and which he had just referred to. Mr. Cassal wished to state that his approval of the Werner Schmid process was mainly based upon its value for the analysis of decomposed milk. If a large number of analyses of fresh milk had to be done, and something else at the same time, the Adams process should be adhered to, for the simple reason that it would go on automatically. That, however, did not detract from the superior value of the Werner Schmid process when employed under specific circumstances.

Mr. Bernard Dyer thought that Mr. Cassal had, he was sure unintentionally, hardly treated Mr. Stokes quite fairly, though he (Mr. Dyer) agreed with Mr. Cassal that it would have been perhaps better that they should not have been troubled with a lengthy description of an apparatus which they were afterwards advised not to use. One of the features of the Schmid process was that one need not trouble to take off all the ether, but could stop it at any graduated point which one might think desirable. Mr. Cassal, however, had said that he did not consider that fractional removal was a good method of working, but that it was much better to take off the whole of the ether at one operation. Now it seemed to him that Mr. Stokes had devised a simple substitute for the original Schmid tube, by means of which he did take off the whole of his ether, thus doing exactly what Mr. Cassal would do with the original tube, on which he had the graduations, but thought it unnecessary to make use of them. If he remembered rightly, Mr. Stokes had told them on previous occasions that the method of pipetting and not troubling to remove the whole of the ether gave results which were very satisfactory indeed.

The President asked Mr. Stokes to state what was the number of analyses which he considered a man could conscientiously and honestly make in a day by means of the process before them.

Mr. Stokes replied that he considered the advantage to be this: that whereas it was impossible by the old process to analyse a sample in half-an-hour, it could easily be done by the method which he had brought forward.

The President said, that he looked upon methods which were said to give results in such a short time, with the greatest suspicion. Fat could not well be dried in an extraction-flask under a quarter of an hour, and the flask itself would have to stand before it could be accurately weighed for about 10 minutes, which almost made up the half-hour given by Mr. Stokes. He could see no possible object or advantage in these rapid analyses. They were all obliged to Mr. Stokes for bringing the Werner Schmid process so prominently before them, and for proving that it was capable of giving good results. Yet, having heard all that had been urged in favour of the process, he (Mr. Hehner) could yet not see where its advantage over the excellent Adams method lay. That process was absolutely automatic, and required the least possible amount of attention, which was a more important point for the analyst than extreme rapidity. He was of opinion that it would be far better for public analysts to stick to the Adams process, which had been universally accepted as being the most accurate one, 
unless any other process effected a decided improvement upon it. For his own part, he could not see that the method so strongly recommended by $\mathrm{Mr}$. Stokes possessed such decided advantage.

Mr. Cassal said that he had stated that the tube, which formed part of Mr. Stokes' wash-bottle apparatus, was originally suggested by Mr. Chattaway, but he understood Mr. Stokes to say that that was not correct. He therefore thought it necessary to ask Mr. Stokes to explain to the meeting the precise difference between the two forms of apparatus. His own impression was, that at the time the Werner Schmid process was first introduced to their notice, the use of an ordinary tube-not graduated or narrowed -was recommended by a member present, and that then Mr. Chattaway explained that he had devised a modification of the wash-bottle for the purpose of removing the whole of the ether eal solution after the treatment of the milk.

Mr. Stokes, in reply, said the main reason for the modifications which he had introduced was that he required to make his determinations quickly. If he had to wait for every operation he would lose a lot of valuable time, which he could not afford. That brought him to the President's question, namely, how many could a man honestly do in a day? He was hardly in a position to give a definite reply to that question, as he had never had occasion to do fat determination only; but he might say that he had 30 or 40 samples to test in a day, and they had to be done promptly. Mr. Dyer had suggested the excision of what he called the intermediate apparatus. The diagram ("Analyst" xvi. 209) had already been given in the Journal of their Society, and he conceived that a man on first seeing it might consider it to be a good idea, as it really looked so theoretically, and waste time in trying to work it. In order to avoid that, he had shown a simpler apparatus that answered the same purpose could be made for the small sum of $2 \mathrm{~s}$., and which would be of use for other purposes than extracting fat from milk. Coming to Mr. Cassal, that gentleman had said that he found a great advantage in blowing off the whole of the ether. He (Mr. Stokes) quite agreed with him, but if Mr. Cassal meant to inform him that ether shaken up with the acid fluid would separate as rapidly in the long tube he had hitherto employed as it would in the short bulbs now before the meeting, he would be surprised indeed. For his own part, he believed that some day Mr. Cassal would adopt the apparatus which he had brought forward, and would admit that it had advantages over any hitherto employed for the purpose.

The following "Notes from the Khedivival Laboratory," by H. Droop Richmond, were taken as read :-

1. The relation between Specific Gravity, Fat, and Solids not fat in the milk of the Gamoose.

2. The estimation of Iodoform.

3. The testing of Petroleum.

This terminated the proceedings of the Society. 
Rapid valuation of Commercial peptones. By M. A. Denaeyer. (Journal de Pharmacie Anvers. Novembre, 1891).-Alcohol of $95 \%$ added in excess to concentrated solutions of meat peptone precipitates undigested albumins, albumoses, pure peptone and gelatin. On the other hand the alcohol separates by solution:-

(1.) The extractive principles of meat (carnine, creatines, creatinines, \&c.); (2) the products of decomposition of albumins (leucine, tyrosine, aspartic acid, \&c.); (3) the products of decomposition of gelatins (alanine, glycocoll, amido-butyric acid, \&c.).

It follows from these facts that alcohol constitutes an excellent agent for the valuation of commercial peptones; the larger the amount of the precipitate the greater will be the strength of the peptone in the nutritive elements; albumoses, peptone, acidalbumins.

We must remember that albumoses and true peptone are only found in peptones produced by the digestion by means of gastric juice; the acid-albumins which enter into the composition of artificial peptones (vapeur peptones?) have apparently, as far as assimilation is concerned, no higher value than ordinary albumin.

The determination in a peptone of the matters soluble in alcohol is made by dissolving 2 grms. of peptone, calculated as dry matter, in about 10 c.c. of water. This solution is precipitated by 100 grms. of alcohol, and the mixture is allowed to stand for 24 hours in a cool place. The alcoholic solution becomes quite clear; it is decanted, and the precipitate washed, the alcohol distilled off and the residue evaporated to dryness in a basin on a water bath. The desiccation is completed in an oven at $105^{\circ} \mathrm{C}$. to constant weight.

In the same way the weight of the alcoholic precipitate is taken after complete drying.

A well-prepared meat peptone should not give above 30 per cent. of alcoholic extract, but commercial preparations are found which yield as much as 60 per cent. These extracts then contain besides creatines and normal extractive bases, great quantities of the products of decomposition of the albumins (leucine, tyrosine, aspartic acid, caproic acid, \&c.), and of the gelatins (glycocoll, leucine, alanine, amido-butyric acid, \&c.) of muscular tissue.

In fact a few drops of the alcoholic solution evaporated on a glass slide show under the microscope leucine and tyrosine with their characteristic forms, besides other things.

These excrementitial products, destitute of alimentary value and formed in defective digestions at the expense of the albuminoids and colloids of meat, represent the deficiency in gelatin, albumin and peptone of these preparations.

The estimation of the alcoholic extracts allows, as will be understood from the above, of the determination of the dietetic equivalent of all preparations of meat peptone: it gives at the same time valuable indications as to the nature of the digestive operations.

It will be remarked that in very acid and long sustained digestions the alcoholic extract of the peptone obtained will be rich in the products of decomposition, whilst the 
concentrated solution of peptone $\left(\frac{2}{\tau_{0}}\right)$ will only yield a small precipitate with the alcohol (30 to 40 per cent. at most).

On the contrary, in digestions faintly acid and well regulated in regard to duration, temperature, weight of pepsine, hydrochloric medium, \&c., the alcoholic extract which the peptone yields will be small, but on the other hand the precipitate of gelatin, albumoses, and peptone very abundant (rising to 70 per cent.).

These assays are very interesting; we recommend them to our confrères. By a simple precipitation with alcohol they will be enlightened as to the respective merits of the preparations of peptone which they purchase.

C. W. H.

On the Grading of Pepper. By H. Trillich. (Zeit., f. angew. Chem. 1891, p. 516).-The Society of Bavarian Chemists having resolved that the highest permissible limit of ash in black pepper be 5.6, with 2 per cent. of matter insoluble in acid, the author investigated the influence of milling and sifting upon pepper. The mill employed consisted of two grooved steel rollers. The crushed pepper passes on to a sieve, the siftings being separately collected, whilst the coarser particles went back upon the rollers over and over again, until no more would pass through the sieve. The remainder went into another mill, and was sifted once more. Thus 12 different siftings were obtained, which were separately examined. The first and second portions showed a fairly equal mixture of black particles of husk and white particles of the inner berry. The subsequent products become successively lighter up to a certain point, end then again darker until the last consist of greyish black particles, mostly consisting of husk.

The first series of experiments were made with Prima Singapore pepper, the berries containing 3.54 per cent. of ash with 0.09 per cent. of sand. 1,000 grammes contained 0.275 grammes of dust, with 0.08 grammes ash $(29 \%)$, and 49.80 grammes of stalks, with 0.655 ash $(13 \cdot 1 \%)$. 1,250 kilos were ground, and the separate portions gave the following results :-

\begin{tabular}{|c|c|c|c|c|c|c|}
\hline \multirow{4}{*}{$\begin{array}{l}\text { Yo. } \\
1 . \\
2 .)\end{array}$} & \multicolumn{2}{|c|}{ Weight. } & \multirow[b]{2}{*}{ Water. } & \multirow[b]{2}{*}{ Ash. } & \multirow[b]{2}{*}{ Sand. } & \multirow{2}{*}{ Pure Ash. } \\
\hline & kilo. & & & & & \\
\hline & 284 & $22 \cdot 7$ & $13 \cdot 89$ & $3 \cdot 71$ & 0.37 & $3 \cdot 34$ \\
\hline & 20 & & $14 \cdot 10$ & $2 \cdot 86$ & $0 \cdot 15$ & $2 \cdot 71$ \\
\hline 3.) & & & $14 \cdot 22$ & $3 \cdot 04$ & $0 \cdot 27$ & $2 \cdot 97$ \\
\hline 4. & & & $13 \cdot 49$ & $3 \cdot 17$ & $0 \cdot 19$ & $2 \cdot 98$ \\
\hline 5. & 338 & $27 \cdot 1$ & $13 \cdot 16$ & $3 \cdot 30$ & 0.17 & $3 \cdot 13$ \\
\hline 6. & & & $13 \cdot 34$ & $3 \cdot 50$ & $0 \cdot 16$ & $3 \cdot 34$ \\
\hline 7. & & & $12 \cdot 96$ & $3 \cdot 80$ & $0 \cdot 13$ & $3 \cdot 67$ \\
\hline 8.) & & & $13 \cdot 10$ & 3.82 & $0 \cdot 15$ & $3 \cdot 67$ \\
\hline 9.$\}$ & 198 & $15 \cdot 8$ & $12 \cdot 87$ & $3 \cdot 95$ & $0 \cdot 10$ & $3 \cdot 85$ \\
\hline 10.) & & & $12 \cdot 89$ & $5 \cdot 11$ & $0 \cdot 13$ & $4 \cdot 98$ \\
\hline 11. & 218 & $17 \cdot 5$ & $12 \cdot 38$ & $7 \cdot 52$ & 0.09 & $7 \cdot 43$ \\
\hline 12.$\}$ & & & $12 \cdot 91$ & $7 \cdot 50$ & $0 \cdot 10$ & $7 \cdot 40$ \\
\hline
\end{tabular}


The greater portion of the sand, therefore, goes into the first part of the product, the percentage of ash in which is large. Curiously, the amount of ash in the following portions steadily increases, while the sand remains practically the same, but the last two fractions have a much higher amount of ash with still less sand.

The second series of analyses were made upon products similarly obtained with Lampong pepper, which is of lower quality than Singapore. The berries contained 4.50 per cent. of ash with 0.52 per cent. of sand. 1,000 grammes contained 6.004 grammes dust, with $2.704 \mathrm{ash}$, or 45.03 per cent., and 1.957 grammes sand, or 32.58 per cent.; also 1.691 grammes woody pepper portion, with 0.256 ash or 15.14 per cent.; 0.111 sand, or 6.56 per cent., and 4.877 grammes stones. These impurities would raise the percentage of ash and of sand in the pepper to, as near as can be estimated, 5.60 per cent. and 1.50 per cent. respectively.

The following are the analyses of the various fractions:-

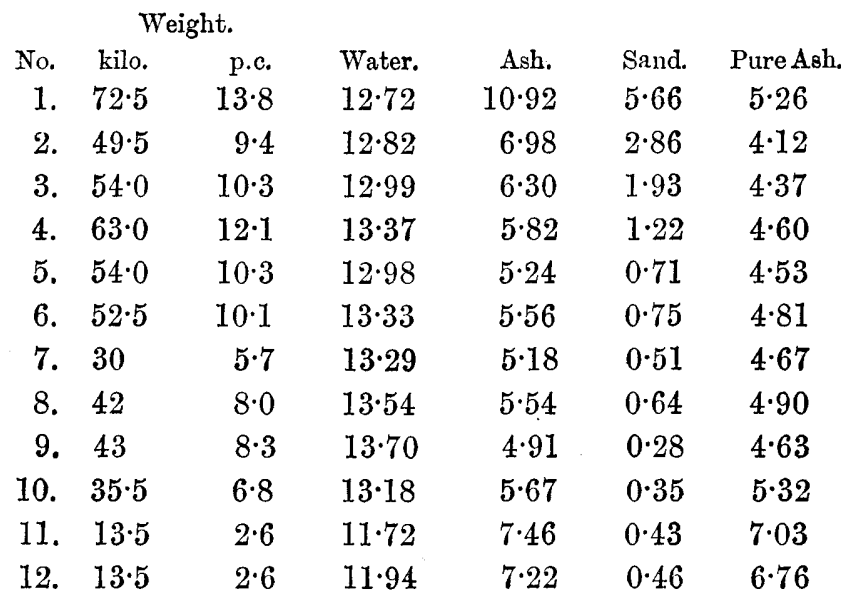

Here again the larger fraction of the sand went into the first fraction, whilst the ash proper steadily rose.

O. H.

The Adulteration of Basic Slag. Morgen. (Read at the 64th meeting of the Deutsch. Naturforsch. u. Aerzte. Through Chem. Zeit.)-The adulteration of basic slag with aluminium phosphate can be detected by the loss on ignition, which, when it amounts to $1 \frac{1}{2}$ per cent. is an almost certain indication of falsification. The addition of Redonda phosphate is detectable by the determination of the specific gravity; the author prefers to use bromoform for this purpose, rather than the potassium-mercuric iodide solution employed by Loges. Besides these tests, the production of a copious precipitate with caustic soda solution is an indication of the presence of the same adulterant. The best method for the quantitative examination of basic slag consists in treating the sample with a 5 per cent. 
solution of citric acid, in which the phosphoric acid natural to the slag is completely soluble while that of Redonda phosphate is not dissolved.

Faffin slag behaves similarly to Thomas slag, save that it remains suspended in bromoform. A new adulterant has been noticed by Loges, containing 4 per cent. of caustic lime, 6.4 per cent. of carbonate of lime, and the remainder calcium fluoride; it is said to be of English origin.

B. B.

[Note By Abstractor.-A letter appears in the Chem. Zeit. 1891, 1449, signed Warth and Wagner, pointing out that the loss on ignition is not to be relied on for detecting the adulteration of basic slag, as samples that have been exposed to air and moisture may absorb a good deal of water and carbonic acid, which they lose on ignition. An error in the contrary direction is imported by the circumstance that the slag may contain ferrous and manganous oxides and absorb oxygen on heating. The presence of calcium fluoride is not necessarily evidence of adulteration, as it may have been introduced for metallurgical reasons.]

The sensitiveness of various Tests for Arsenic. C* O* Curtmann. (Pharm. Rundsch. 1891., ix. 175. Through Chem. Zeit.)-The author has examined a number of tests for arsenic as to sensitiveness, and records the following results :-

1. Sulphuretted hydrogen; $0.01 \mathrm{mg} . \mathrm{As}_{4} \mathrm{O}_{6}$ in 1 c.c. of liquid, gave a slight yellow turbidity after two minutes; $0.001 \mathrm{mg}$. $\mathrm{As}_{4} 0_{6}$ gave a yellowish tinge after 15 minutes; when the dilution was greater no reaction was obtained.

2. Silver nitrate; $0.01 \mathrm{mg} . \mathrm{As}_{4} \mathrm{O}_{6}$ in 1 c.c. gave a slight yellow turbidity after six minutes; the reaction ceased on further dilution.

3. Scheele's reaction; [Ammonium-Copper Sulphate]; $0.1 \mathrm{mg} . \mathrm{As}_{\mathbf{6}} \mathbf{0}_{6}$ in 1 c.c. gave a slight green precipitate immediately; the limit was reached with $0.01 \mathrm{mg}$, which gave a scarcely perceptible turbidity after some time.

4. Bettendorff's method [Stannous chloride in concentrated hydrochloric acid]; $0.1 \mathrm{mg} . \mathrm{As}_{4} \mathrm{O}_{6}$ in 1 c.c. gave a slight brown colouration; $0.01 \mathrm{mg}$. gave no reaction.

5. Gützeit's reaction [Action of arsenical hydrogen upon a very concentrated solution of silver nitrate]; $0.001 \mathrm{mg} . \mathrm{As}_{4} \mathrm{O}_{6}$ in 1 c.c. gave a yellow stain after 30 minutes, which, when moistened, became bright brown. The limit was reached at $0.0001 \mathrm{mg}$. which gave a barely perceptible stain after one hour, the colouration becoming more perceptible on moistening and again drying.

It is therefore possible, by means of Gutzeit's reaction, to detect one part of arsenious anhydride in 10 million parts of solution. The method is, therefore, eminently suitable for testing reagents for analysis, but is far too sensitive for testing pharmaceutical preparations, for which purpose Bettendorff's method is better fitted. 
On the estimation of Mixtures of Saponifiable and Unsaponifiable Fats. M. Hönig and G. Spitz. (Zeit. f. angewandt. Chemie. 1891, p. 565).-The absence of concordant results in analyses of mixtures of the above-mentioned substances made by different chemists, may be traced to the inexactitude of the methods employed. These (putting on one side the iodine and bromine addition processes as entirely useless) are the three following:-

1. The mixture is saponified with alcoholic potash, the unsaponified portion being caused to separate either by boiling, or by being kept warm for some time. The separation is never complete, and, consequently, the results are always too low.

2. The soluble soap obtained by saponification with alcoholic potash is either as such, or after conversion into an insoluble soap, thoroughly dried and exhausted with ether or petroleum ether. This process only gives exact results when the soap is absolutely dry, and when the slight solubility of soap in petroleum ether is taken into account. Since the drying and extraction of the soap are both tedious operations, the process cannot be recommended for practical use.

3. The alcoholic solution of soap, obtained on saponification, is repeatedly shaken out with petroleum ether, or extracted in a suitable apparatus. This method, as shown by Morawsky and Dembsky (Dinglers Polyteckn. 1885, p. 39), gives rigidly accurate results when certain precautions are taken. Messrs. Hönig and Spitz propose a modification which, without interfering with the exactness of the process, considerably shortens the time of its execution. This consists in using, instead of water, 50 per cent. alcohol for washing the petroleum ether layer, to remove the small quantity of soap taken up by it. By this means the two layers of fluid separate almost immediately. The two processes recommended are as follows :-

(A.) 7 to 10 grms. of the fat are boiled under a reflux condenser, with 20 to 25 c.c. of strong alcoholic potash and as much alcohol for 5 to 10 minutes; 30 to 40 c.c. of water added, and the whole boiled up once. After cooling, the soap solution is run into a separatory funnel, the flask rinsed out with 50 c.c. of alcohol, then with 50 c.c. petroleum ether, and the whole thoroughly well shaken. The alcoholic soapy layer quickly subsides, and is run off. The petroleum ether layer is now shaken out 2 or 3 times with 10 to 15 c.c. of 50 per cent. alcohol, the washings being added to the original alcoholic soap solution. The petroleum ether is emptied into a tared flask. The alcoholic soap. solution is shaken out with repeated quantities of petroleum ether, until a drop of the latter leaves no fatty stain after evaporation on paper. The dissolved soap is removed from each of the petroleum ether washings by being shaken out thrice with 50 per cent. alcohol. The united petroleum ether washings are distilled off, a small weighed piece of pumice stone being added to prevent bumping. The last portions of petroleum ether are removed by heating the flask, and blowing into it. Petroleum ether boiling between 50 and $70^{\circ} \mathrm{C}$. should be used. The alcoholic soap solution may, after boiling off the alcohol, be used for the estimation of the saponifiable fats by the usual methods. The whole process can be performed in an hour. 
(B.) When many determinations have to be made at one time, the authors propose a
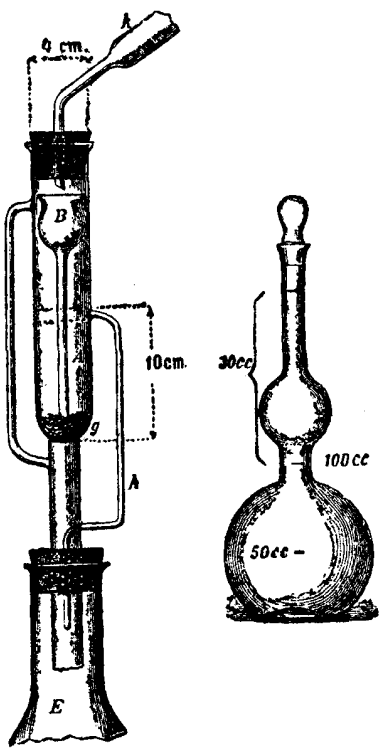
method of continuous extraction of the soap solution instead of shaking out, using for this purpose the modified form of a Soxhlet extracting apparatus shown in the accompanying illustration. Instead of the syphon, a small tube $(h)$ is inserted about half way down the container $A$, and after one right-angled bend, passes downwards and enters the lower tube attached to the evaporating flask. A small thistle-headed funnel of such a length that its head is a short distance below the cork of the container, is inserted, its lower end dipping into a layer of glass beads about 1 centimeter deep. The alcoholic soap solution which, after dilution with water, should amount to about 50 c.c., is shaken up in the flask with about 20 c.c. petroleum ether, poured into the extracting apparatus, the flask again washed out with petroleum ether, and finally with 50 per cent. alcohol. The surface of the soap solution should be about half a centimeter below the mouth of the draining off tube.

After connection with the extraction flask, the small funnel is inserted, and 20 c.c. petroleum ether carefully poured in, the apparatus connected with a reflux condenser, and the ether kept boiling until it runs off quite colourless, and the soap solution is perfectly clear. The ether gradually becomes turbid from the soap dissolved; this must be removed by shaking out the solution several times with 50 per cent. alcohol in a separatory funnel.

(C.) If an approximate estimation only be required, the operation may be simplified as follows:-The saponification is effected in the flask shown in the figure, and which contains about 100 c.c. to the mark in the middle neck, this space being divided into two by a mark in the bulb. The amount contained between the marks in the upper and lower necks is exactly 30 c.c. ; 2 to 3 grms. of the fat are saponified with alcoholic potash, after cooling, filled up to the 50 c.c. mark with alcohol, then made up to 100 c.c. with water, 30 c.c. petroleum ether added, and the whole repeatedly shaken. After perfect separation of the ether, 20 c.c. of it are pipetted off, placed in a tared flask, the ether driven off, the fat weighed, and the requisite calculation made. This method, as shown by examples, gives results to within 1 per cent. of the truth.

For the estimation of water, which, with the assistance of ammonia or ammonium carbonate, may be incorporated into the oil to the extent of 30 per cent., without being detected by superficial observation, the authors recommend 20 grms. of the well-mixed sample to be dissolved in about 100 c.c. petroleum ether, and allowed to stand for an hour, filtered through a tared filter into a tared flask, taking care no water reaches the filter. The residue and filter are washed several times with petroleum ether, the 
ether driven off from the flask and filter, and the two weighed. The purified fat thus left may be advantageously used for analysis.

The water may be also estimated by dissolving 15 to 20 grms. of the fat in petroleum ether, placing the liquid in a burette filled up to the lowest mark with water, and after standing some time, directly reading off the water. The dregs are estimated by filtering the solution through a tared filter, washing with petroleum ether, drying and weighing.

W. J. S.

The Determination of Earthnut Oil in Olive Oil. Holde (Mitt. König. Tech. Versuchs., 1891, 9, 105, through Chem. Zeit.).-The usual method of detecting and determining arachis or earthnut oil in olive oil, depending upon the isolation of arachidic acid needs modification in the case of oils containing only 5-10 per cent. of arachis oil, 40 grms. of the suspected oil being taken instead of the 10 grms. ordinarily prescribed, Moreover the arachidic acid isolated by extraction of the palmitic acid which accompanies it when the lead salts insoluble in ether are decomposed by hydrochloric acid must be repeatedly recrystallized from 90 per cent. alcohol until its melting point ceases to rise. unless it be over $70^{\circ} \mathrm{C}$. at the first trial.

B. B.

Adulteration of Dried Mushrooms, P. E. Alessandri (Zeits. Nahrungsmittel-Untersuchung $u$. Hygiene, 1891, 5, 79, through Chem. Zeit.).-The author found in samples of dried mushrooms offered for sale, about 30 per cent. of unequally thick white dises, puckered or crumpled in aspect and brownish yellow (not chestnut brown) at the edges, which showed no wrinkles, hollows, or wavy lines like those on true mushrooms. They were coloured blue by iodine and when examined microscopically appeared to be simply pieces of turnip, dried discs of which presented the same appearance and behaviour.

B. B.

Remedy for “Bumping." E. Pieszezek (Chem. Zeit. 1891, 15, p. 1126.)The plan advocated consists in placing a glass tube about 5-8 cm. in length, and 5-10 $\mathrm{mm}$. in width (the exact dimensions depending upon the bulk of liquid to be boiled) and closed at the upper end, resting against the side of the flask or other vessel to be heated, so that it stands nearly vertical with its open sharp-edged end pointing downwards. Boiling goes on quietly when once started, the bubbles making their appearance at the lower end of the tube. On cooling, the liquid rises in the tube which must therefore be raised and allowed to again become full of air before beginning the boiling again. The tube is best provided with a book of platinum wire fixed in the upper end for ease of handling. The device is said to be efficient even for liquids containing heavy precipitates such as barium sulphate, and lead sulphate, and is also recommended for the Reichart-Vollny process.

B. $B$. 